\title{
Effect of Concentration of Mo on The Mechanical Behavior of UMo Fuel: An Atomistic Study
}

Asmat Ullah ( $\square$ asmat@hrbeu.edu.cn )

Harbin Engineering University https://orcid.org/0000-0001-5538-5241

Muhammad Ado

Harbin Engineering University

Simon Adede

Harbin Engineering University

\section{Research Article}

Keywords: Nanoindentation, MD simulation, UMo fuel

Posted Date: August 3rd, 2021

DOI: https://doi.org/10.21203/rs.3.rs-698716/v1

License: (1) This work is licensed under a Creative Commons Attribution 4.0 International License.

Read Full License 


\title{
Effect of concentration of Mo on the mechanical behavior of UMo fuel: An atomistic study
}

\author{
Asmat Ullah*, Muhammad Ado, Simon Adede \\ College of Nuclear Science and Technology, Harbin Engineering University, Harbin, China.
}

For correspondence

Asmat Ullah

asmat@hrbeu.edu.cn

CNST, HEU, Harbin, China 


\begin{abstract}
We performed molecular dynamics simulation on nanoindentation of Uranium Molybdenum alloys using spherical indenter. A ternary potential developed for UMoXe was utilized. We calculated the updated values for hardness and reduced elastic modulus at different concentrations of Mo. The whole process of deformation and dislocation analysis was visualized using OVITO. We found an increase in deformation with increase in stress while dislocations are not found anyhow induced defects have been distributed throughout the simulation cell randomly. The increase in concentration affected the hardness and reduced elastic modulus significantly.
\end{abstract}

Keywords: Nanoindentation; MD simulation; UMo fuel; 


\section{Introduction}

Low Enriched Uranium (LEU) fuels play an indispensable role in peaceful purposes of nuclear energy. Uranium Molybdenum (UMo) is a LEU alloy which is considering an attractive fuel for fast and pressurized water reactors [1-3]. Besides them UMo alloys have applications in reactors such as SORA [4], RERTR [5] and Dounreay Fast Reactors [6]. It is ease in fabrication with inviting characteristics such as high thermal conductivity, good structural stability and reliable mechanical strength. Understanding the integrity during operations whether normal or transient or anticipated faults is of high importance for the better functionality of a fuel in a nuclear reactor. The fission products are only released from a fuel plate during irradiation if a defect exists in the cladding that provides a path for fission gas to escape [7]. These defects under stress and temperature fields eventually lead to swelling or pores which ultimately either limit the performance or permanent failure of the fuel. Waldron et.al [8] reported that $5.5 \mathrm{wt} \%$ Mo doped into $U$ showed enhanced mechanical properties upto high temperature. As declared by another group on experimental basis that the brittleness and fracture are dependent on Mo concentration [9]. In this work we performed a number of MD simulations using LAMMPS code to study nanomechanical characteristics of UMo fuel at different atomic percent Mo. A spherical indenter of defined radius was used whose load versus depth data is recorded. Dislocations creation and deformation were tracked using OVITO.

\section{Method}

MD simulations were performed using Large scale Atomic/Molecular Massively Parallel Simulator (LAMMPS) [10]. The EAM potential developed by Smirnova [11] for U-Mo-Xe is used for our binary system. Periodic boundary conditions were applied in the $\mathrm{x}$ and $\mathrm{y}$ while shrink style was used along the $\mathrm{z}$ axis. Two types of groups were created and a simulation cell of 
$40 \mathrm{~A}^{0}$ in each direction. The relaxation was conducted using the NVT ensemble at $300 \mathrm{~K}$ using the velocity Verlet algorithm at $300 \mathrm{~K}$ with a time step of $1 \mathrm{fs}$ for 100,000 steps. The system was relaxed again at $100 \mathrm{ps}$ for the same number of steps using NVE ensemble [12]. Langevin's thermostat [13] was adopted to fix the temperature at $300 \mathrm{~K}$. A rigid spherical indenter was used with radius of $35 \mathrm{~A}^{0}$, and the force on each atom was calculated. A non atomic repulsive sphere exerts a force on the atomic layer which can be quantified using equation (1)

$$
F=-K(r-R)^{2}
$$

where $\mathrm{R}$ is the radius of the indenter and $\mathrm{r}$ is the distance from the atom to the center of the indenter. The speed of the indenter during loading and unloading was $0.1 \AA$ Ass which will penetrate it to a maximum depth of $20 \AA$. We conducted simulations for four different concentrations of Mo in the alloy. The atomistic events at different input conditions were analyzed and visualized via Open Visualizations Tool (OVITO) [14].

\section{Interatomic potential}

An interatomic potential for UMo system with Xe is developed within the framework of an embedded atom model using a force matching technique and a dataset of ab initio atomic forces. The verification of potential proves that it is suitable for investigation of various compounds existing in the system as well as for simulation of pure elements: U, Mo and Xe. The obtained values for lattice constants, thermal expansion coefficients, melting temperatures, elastic properties and formation energies are consistent with the experimental and ab initio data. The development of this potential has been performed within the framework of the embedded atom method (EAM) $[12,13]$ which takes into account the many particle interactions. This model is shown to be convenient in the cases of binary [15] systems and pure uranium [16]. The potential of the system can be represented mathematically as 


$$
U=\sum_{i<j} \varphi_{\alpha \beta}\left(r_{i j}\right)+\sum_{j} F_{\alpha}\left(\rho_{j}\right), \quad \rho_{j}=\sum_{j \neq i} \rho\left(r_{i j}\right) \quad \alpha, \beta=U, M O, X e
$$

where pair potential is $\varphi_{\alpha \beta}$ and $r_{i j}$ is the interatomic distance between any two given atoms. $\alpha, \beta=U, M O, X e$ and $\rho_{j}$ is an effective electron density. At a given cut off radius both the functions $\rho$ and $\varphi$ fall to zero. The function $F_{\alpha}$ in the second term is standing for many body effects and is a non linear embedding function.

\section{Results}

Nanoindentation is generally the most common technique to study the nanomechanical quasistatic properties of a sample. In this process we made use of substrate to hold at fixed position the target so it may prevent atoms from shifting during indentation. The schematic representation of nanoindentation using a spherical indenter is shown in figure 1.

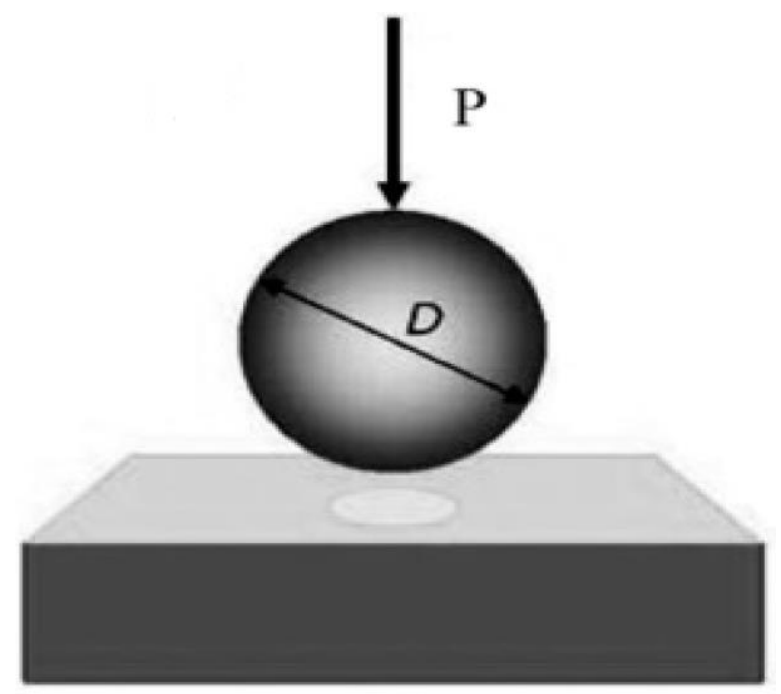

Figure:1 Schematic diagram of nanoindentation using spherical indenter 
The process of nanoindentation consists of loading and unloading portions which are visualized through OVITO with respect to time and the residual impact of the spherical indenter on the surface of the target has been shown in the figure 2 .
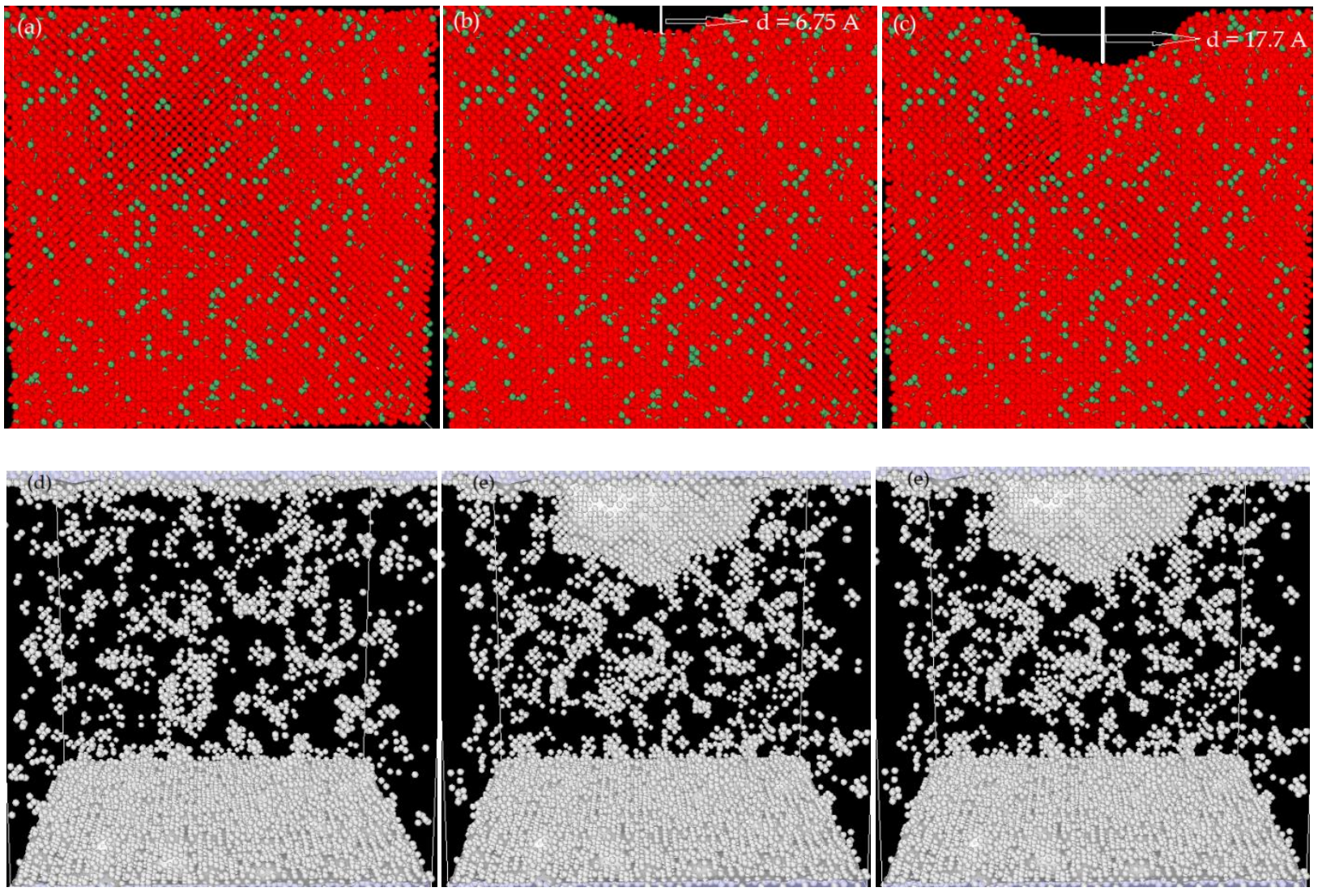

Figure: 2. From (a)-(c) shows the deformation mechanism while (e)-(f) show the DXA analysis

\section{at different time intervals.}

The maximum value of the penetration depth of the sample into the sample was recorded $20 \mathrm{~A}^{0}$.

In figure 2 from (a)-(c) is showing in green the Mo atoms while drawn in red are U. During analysis it was observed that the impact of applied stress is not producing any permanent dislocations but the defects induced due to applied stress are scattered randomly. At different timescales we have identified the penetration depth of the indenter by slicing the simulation cell 
in OVITO. We conducted the dislocation analysis by involving the Dislocation Analysis (DXA) identifier and the results at different simulation times are presented in figure. 2 from (e) to (f). Just like in ceramics [17] non existence of dislocations has been found in UMo alloy at all the said concentrations of Mo.

In the quasistatic study of nanoindentation the loading part is assumed to be the plastic while the unloading curve is representing the elastic regime. Figure. 3 tells us that just like all the metal the target of UMo is also hardening as the load is increasing with the depth.

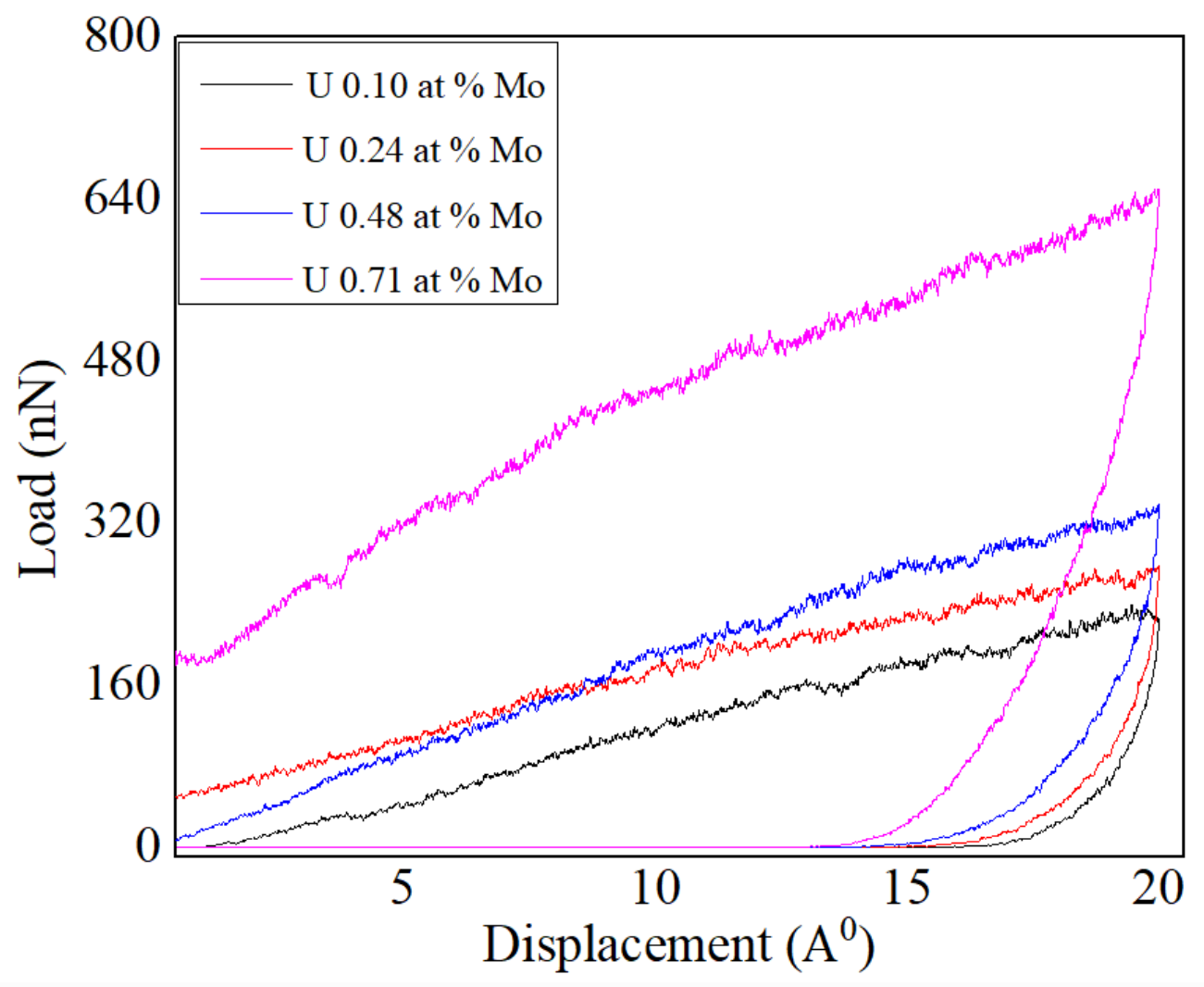

Figure: 3 Loading-unloading processes during nanoindentation 
No significant pop in were observed. The absence of dislocations and these pop in the process record no plastic events. We observed that increase in the density of Mo required higher load to penetrate to the same depth and significant increase is measured with 0.71 at $\%$ Mo.

Hardness is the resistance to local deformation such as indentation, scratches or plastic deformation. Mathematically the hardness is given by

$$
H=\frac{P_{\max }}{A_{c}}
$$

where $P_{\max }$ is representing the maximum value of the force applied by the indenter and $\mathrm{A}_{\mathrm{c}}$ is the residual contact area which is given by $A_{c}=\pi R h_{c}$. In order to predict the strength of resistance to deformation at different levels of Mo concentration we worked on the reduced elastic modulus which can be obtained from the unloading data and is mathematically given by

$$
E_{r}=\frac{1}{2 \beta} \frac{\sqrt{\pi}}{A_{c}} \frac{d p}{d h}
$$

where $\beta$ is a constant carrying information about shape of the indenter and its value for spherical indenter is 1.034. $\mathrm{E}_{\mathrm{r}}$ is equivalent reduced elastic modulus and $\frac{d p}{d h}$ is the stiffness which can be obtained from the initial part of unloading curve. In order to fit the function at the maximum indenter's displacement, the initial process of unloading can be regarded as elastic deformation (Pharr 1992). Therefore, we choose different intervals in the unloading process for linear fitting and found out the mean value. Unloading part of the P-h curve is usually fitted using the following function,

$$
P=\alpha\left(h-h_{f}\right)^{m}
$$


and

$$
S=\left(\frac{d p}{d h}\right)_{h=h_{\max }}=\alpha m\left(h_{\max }-h_{r}\right)^{m-1}
$$

$h_{\max }$ is the maximum indentation depth and $h_{r}$ is the residual depth after unloading whereby $\alpha$ and $m$ are constants with values 1.5 for each in case of a spherical indenter [18]. The slope of each unloading curve is calculated for obtaining the mechanical properties of UMo.

An equivalent way to obtain elastic modulus is

$$
\frac{1}{E_{r}}=\frac{1-v_{1}^{2}}{E_{1}}-\frac{1-v_{2}^{2}}{E_{2}}
$$

where " $\mathrm{v}_{1}$ " and " $\mathrm{v}_{2}$ " represent poison's ratios and $\mathrm{E}_{1}$ and $\mathrm{E}_{2}$ are the elastic moduli of sample and indenter respectively. The values of poison's ratios and elastic modulus for diamond indenter are 0.07 and $1141 \mathrm{GPa}[19]$ while for the sample are 0.23 [20] and $91 \mathrm{GPa}$ [22] respectively. The values of $\mathrm{H}$ and $\mathrm{E}_{\mathrm{r}}$ are tabulated in table.1

Table: 1 Hardness and reduced elastic modulus of UMo alloy at different Mo atomic percent

\begin{tabular}{|c|c|c|c|c|c|}
\hline Alloy & $\mathrm{P}_{\max }$ & $\mathrm{h}_{\mathrm{c}}$ & $\mathrm{A}_{\mathrm{c}}$ & $\mathrm{H}$ & $\mathrm{E}_{\mathrm{r}}$ \\
\hline & $\mathrm{nN}$ & $\mathrm{A}^{0}$ & $\mathrm{x} 10^{-20} \mathrm{~m}^{2}$ & $\mathrm{GPa}$ & $\mathrm{GPa}$ \\
\hline U0.71at\%Mo & 650.4 & 15.9 & 1747.4 & 37.2 & 93 \\
\hline U0.48at\%Mo & 338.5 & 17.1 & 1879.29 & 18.0 & 119 \\
\hline U0.24at\%Mo & 277.6 & 18.0 & 1978.2 & 14.0 & 94 \\
\hline U0.10at\%Mo & 243.1 & 18.7 & 2055.13 & 11.8 & 101 \\
\hline
\end{tabular}


It can be seen from Fig. 4 that concentration of Mo is directly proportional to $\mathrm{H}$ of the material. The elastic modulus predicted by Smirnova [21] is $76 \mathrm{GPa}$ and Nomime [22] is 82.9-91.5 GPa for U-10wt \% Mo alloys which are found close to our findings. $10 \mathrm{wt} \%$ is equivalent to 0.23 at $\%$. The small difference is due to geometry of the sample used together with the different order of the heat treatment.

Doerner and Nix et.al [23] suggested that linear fitting of the unloading data may be used to determine the stiffness, from which the hardness and modulus can be derived. We recommend that initially we have to evaluate the stiffness before the evaluation of $\mathrm{H}$ and $\mathrm{E}_{\mathrm{r}}$. The evaluated slopes will be used to determine hardness and reduced elastic modulus and explanation to this step is mentioned earlier. In order to fit the function at the maximum indenter's displacement, the initial process of unloading can be regarded as elastic deformation (Pharr 1992). Therefore, we choose different intervals in the unloading process for linear fitting and found out the mean value. The fitting models of unloading curves of different densities of Mo in UMo can be found from their corresponding slope by an appropriate section on the unloading curve. In the Fig. 4 (a) and (b) in the black dots are representing the fitted data obtained through simulations but in the red lines are shown the fitted curves. 

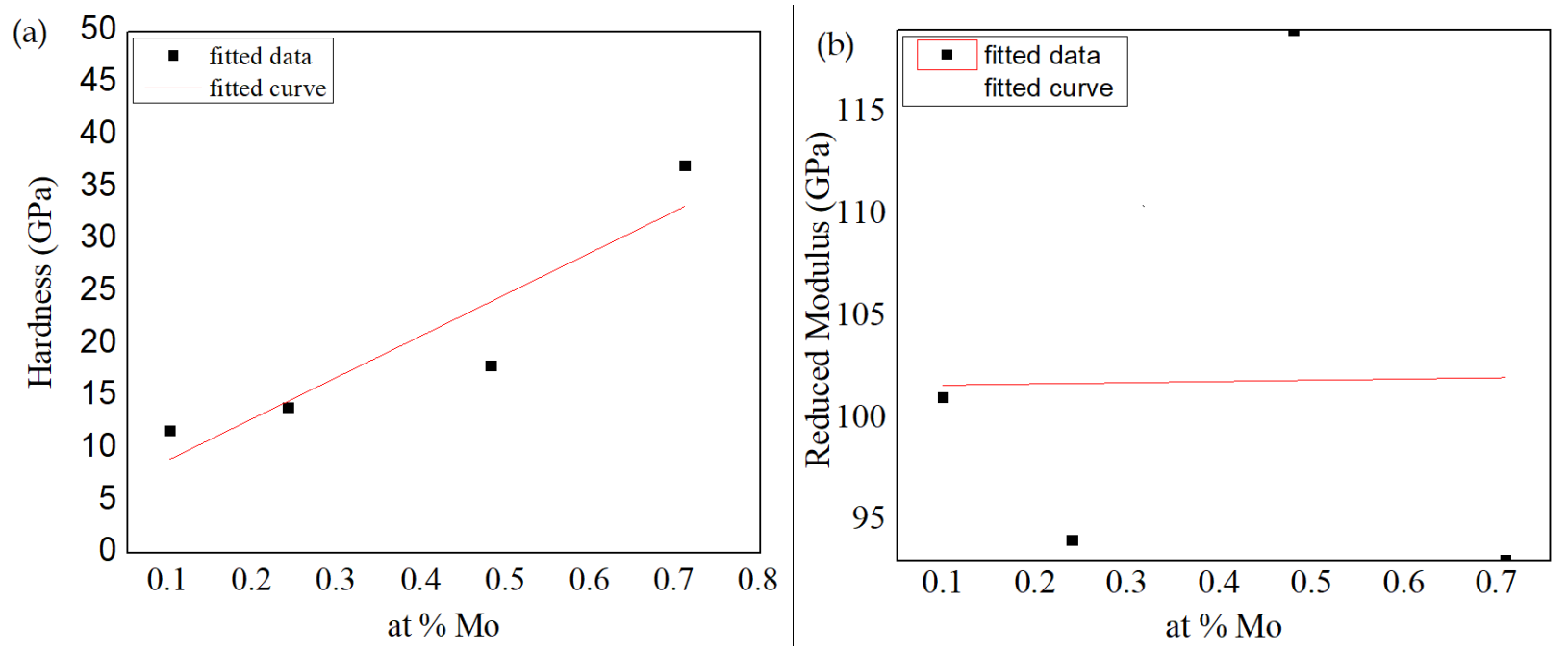

Figure: 4 Hardness of the UMo alloy at $300 \mathrm{~K}$ at different concentrations of Mo

From the fitted curves we can see that the hardness is directly proportional to the percent value of Mo in UMo fuel and $\mathrm{E}_{\mathrm{r}}$ is increasing but very slightly with increase in the concentration.

\section{Conclusion}

Atomistic simulations on nanoindentation was carried out using molecular dynamics simulation code LAMMPS. The U-Mo-Xe ternary EAM potential is used in this simulation. Diamond made spherical indenter investigation was carried out in order to determine the updated values for the hardness and elastic modulus of UMo fuel. Using OVITO we visualized the deformation mechanism which guided us that the atoms with the application of external forces are found in the state of motion and the area under the indenter tip is deforming while the DXA analysis confirmed that there observed no dislocations at all the said concentration of Mo. The $\mathrm{H}$ is increasing with increase in Mo concentration but $\mathrm{E}_{\mathrm{r}}$ is fluctuating. 


\section{Declarations}

Funding: This research work was financially supported by China Scholarship Council and College of Nuclear Science and Technology, Harbin Engineering University, China.

Conflicts of interest/Competing interest: No conflict of interest between the authors on the current version of manuscript.

Availability of data and material: The total data will be available upon request from editor

Code availability: N/A

Authors' contributions: All the authors contributed equally 


\section{References}

[1] Material Properties of Unirradiated Uranium Molybdenum (U-Mo) Fuel for Research Reactors, International atomic energy agency, Vienna, 2020.

[2] Beghi, G., Gamma Phase Uranium-Molybdenum Fuel Alloys, Rep. EUR 4053 e, EURATOM Joint Nuclear Research Center Ispra Establishment, Brussels (1968).

[3] McGEARY, R.K., et al., Development and Properties of Uranium-Base Alloys Corrosion Resistant in High-Temperature Water. Part I Alloys Without Protective Cladding, Rep. WAPD127, Westinghouse Electric Corp. Atomic Power Div., Pittsburgh, PA, (1955).

[4] Larrimore, J. A. "The SORA Reactor:design status report "Seminar on intense neutron source , USAECENEA, Santa Fe, New Mexico, (Sept. 1966).

[5] Ivanov. S.N., et al., Materials-technology investigations of fuel elements, irradiated in a reactor at the Obinsk Nuclear Power Plant, after standing 38 years in a depository,Atomic Energy 88 (2000) 184-189.

[6] G. Beghi “Gamma phase Uranium Molybdenum fuel alloys" Joint Nuclear Research Center Ispra Establishment, Italy Metallurgy and Ceramics, September 1968.

[7] IAEA Nuclear Energy Series, Good Practices for Qualification of High Density Low Enriched Uranium Research Reactor Fuels, No. NF-T-5.2, International Atomic Energy Agency, Vienna (, 2009.

[8] M. B Waldron, R.C Burnett, S.F Pugh The mechanical properties of UMo alloys Atomic Energy Research Establishment, Harwell, Berkshire, 1958.

[9] R.F. Hills, B. R. Butcher and B. W. Howlett The mechanical properties of quenched UMo alloys Journal of Nuclear Materials 11,2 (1964) 149-1 62. 
[10] S. Plimpton, Fast parallel algorithms for shorterange molecular dynamics, J. Comput. Phys. 117 (1995) 1e19.

[11] D.E. Smirnova, A.Y. Kuksin, S.V. Starikov, V.V. Stegailov, Z. Insepov, J. Rest, and A.M. Yacout (2013), "A ternary EAM interatomic potential for U-Mo alloys with xenon", Modelling and Simulation in Materials Science and Engineering, 21(3), 035011. DOI: 10.1088/09650393/21/3/035011.

[12] Daw M and Baskes M 1984 Phys. Rev. B $296443-53$

[13] Belashchenko D K 2012 High Temp. 50 331-9

[14] A. Stukowski, Visualization and analysis of atomis simulation data with ovito - the open visulaization tool, Modeling and Simulation of Materials Science and Engineering 18 (2010) 015012.

[15] Starikov S, Insepov Z, Rest J, Kuksin A Y, Norman G, Stegailov V and Yanilkin A 2011 Phys. Rev. B 84104109

[16] Smirnova D, Starikov S and Stegailov V 2012 J. Phys.: Condens. Matter 24015702

[17] P. V. Nerikar, D. C. Parfitt, L. A. Casillas Trujillo, D. A. Andersson, C. Unal, S. B. Sinnott, R. W. Grimes, B. P. Uberuaga, and C. R. Stanek Segregation of xenon to dislocations and grain boundaries in uranium dioxide PHYSICAL REVIEW B 84, 174105 (2011)

[18] Jiri Nemecek Nanoindentation in material science doi:10.5772/2829 (2012)

[19] M. Mustafa Azeem, W. Qingyu \& M. Zubair “Atomistic simulations of nano indentation response of irradiation Defects in Iron” Sains Malaysiana 48(9)(2019): 2029-2039 [20] https://www.schoolmykids.com/learn/interactive-periodic-table/poisson-ratio-of-all-theelements 
[21] D. E. Smirnova, S. V. Starikov, V. V. Stegailov, Interatomic potential for uranium in a wide range of pressures and temperatures, J. Phys.: Condenced matter 24 (1) (2012) 015702.doi:10.1088/0953-8984/24/1/015702.

[22] Nomine A, Bedere D and Miannay D 1974 Physical metallurgy of uranium alloys Proc. 3rd Army Materials Technical Conf. (Vail, CO) ed J Burke et al pp 657-99

[23] M. F Doerner, W. D. Nix A method for interpreting the data from depth sensing indentation instruments J. Mater. Res 1 (4), 1986 